\title{
Non-caveolar caveolin-1 expression in prostate cancer cells promotes lymphangiogenesis
}

\author{
Zeyad D. Nassar ${ }^{1}$, Michelle M. Hill' ${ }^{2}$, Robert G. Parton ${ }^{3}$, Mathias Francois ${ }^{3}$, \\ Marie-Odile Parat ${ }^{1}$ \\ ${ }^{1}$ The University of Queensland, School of Pharmacy, QLD, Australia \\ ${ }^{2}$ The University of Queensland Diamantina Institute, The University of Queensland, Translational Research Institute, QLD, Australia \\ ${ }^{3}$ The University of Queensland, Institute for Molecular Bioscience, QLD, Australia \\ Correspondence to: Marie-Odile Parat, email: m.parat@uq.edu.au \\ Keywords: caveolae, prostate cancer, lymphatic endothelial cells, lymphangiogenesis, VEGF \\ Received: May 29, $2015 \quad$ Accepted: July 30, $2015 \quad$ Published: August 03, 2015
}

This is an open-access article distributed under the terms of the Creative Commons Attribution License, which permits unrestricted use, distribution, and reproduction in any medium, provided the original author and source are credited.

\section{ABSTRACT}

Lymphangiogenesis allows prostate cancer (PCa) lymphatic metastasis, which is associated with poor prognosis and short survival rates. Caveolin-1 (Cav-1) is a membrane protein localized in caveolae, but also exists in non-caveolar, cellular or extracellular forms. Cav-1 is overexpressed in $\mathbf{P C a}$, promotes prostate tumour progression and metastasis. We investigated the effect of caveolar and non-caveolar Cav-1 on PCa lymphangiogenic potential. Cav-1 was down-regulated in PC3 and DU145, and ectopically expressed in LNCaP cells. The effect of PCa cell conditioned media on lymphatic endothelial cell (LEC) viability, chemotaxis, chemokinesis and differentiation was assessed. The effect of Cav-1 on PCa cell expression of lymphangiogenesismodulators VEGF-A and VEGF-C was assessed using QPCR and ELISA of the conditioned medium. Non-caveolar Cav-1, whether exogenous or endogenous (in LNCaP and PC3 cells, respectively) enhanced LEC proliferation, migration and differentiation. In contrast, caveolar Cav-1 (in DU145 cells) did not significantly affect PCa cell lymphangiogenic potential. The effect of non-caveolar Cav-1 on LECs was mediated by increased expression of VEGF-A as demonstrated by neutralization by anti-VEGF-A antibody. This study unveils for the first time a crucial role for non-caveolar Cav-1 in modulating PCa cell expression of VEGF-A and subsequent LEC proliferation, migration and tube formation.

\section{INTRODUCTION}

Lymph node (LN) metastasis significantly affects prostate cancer prognosis [1]. Lymphangiogenesis, the formation of new lymphatic vessels from pre-established ones, is one of the mechanisms that promote prostate cancer LN metastasis. A positive association between lymphangiogenic factors such as VEGF-A, -C, and -D, and lymph node metastasis, pathological grade, and poor prognosis of the disease is documented [2-6]. Understanding the biology of PCa lymphangiogenesis, and developing therapeutic strategies that interfere with this process, is an active field of research [7]. Together with angiogenesis, lymphangiogenesis is an effective therapeutic target in $\mathrm{PCa}$ [8-10].

Caveolae are small plasma membrane pits $(60-80 \mathrm{~nm})$ with important functions in cellular processes such as signalling, endocytosis, migration, adhesion and trafficking. Two proteins are essential in caveola formation, namely caveolin-1 (Cav-1) and PTRF [11]. Both tumour suppressive and tumour-promoting roles are reported for Cav-1 in cancer, depending on the cancer type, the tumour stage, and the cellular compartment that is analysed [11-15]. In prostate cancer however, overwhelming evidence implicates Cav-1 as being associated with, and mediating, increased aggressiveness; Cav-1 overexpression in prostate cancer clinical samples correlates with disease stage [16], grade [17], metastasis [16], androgen insensitivity [18] angiogenesis [19] and poor outcome [20]. In vitro and preclinical studies further support that Cav-1 expression in prostate cancer cells increases tumour growth, invasion, angiogenesis and ultimately metastasis [18, 21-27]. Cav-1 can be secreted by prostate cancer cells and displays paracrine and endocrine functions $[18,23,24,28]$. Cav-1 is found in the circulation of $\mathrm{PCa}$ patients and has been proposed as a diagnostic, prognostic, or therapeutic efficacy marker [28, 29]. 
Systemic administration of anti-Cav-1 antibody for three weeks to mice orthotopically injected with Cav1 -secreting PCa cells decreases cancer cell volume in lymph nodes [18]. However, there is no published study testing whether manipulating Cav-1 expression in $\mathrm{PCa}$ cells modulates lymphangiogenesis. Moreover, most of the work identifying the effect of Cav-1 expression on $\mathrm{PCa}$ aggressiveness and angiogenic potential [18, 21, 23, 30, 31] precedes the recognition that in the absence of PTRF, cells cannot form caveolae and Cav-1 resides in a different compartment [32] and therefore did not differentiate between the effects of caveolar Cav-1 and non-caveolar Cav-1, which we are now able to dissect out [11, 33-35]. In the current study, we investigated the effect of caveolar and non-caveolar Cav-1 in three PCa cell lines on their lymphangiogenic phenotype, and unveiled a mechanism of Cav-1 pro-lymphangiogenic action in $\mathrm{PCa}$.

\section{RESULTS}

\section{Modulation of Cav-1 expression}

In order to study the role of Cav-1 expression by $\mathrm{PCa}$ cells on lymphangiogenesis, we employed three $\mathrm{PCa}$ cell models in which Cav-1 expression was experimentally manipulated: Cav-1-GFP was exogenously expressed in androgen-sensitive human LNCaP cells, which do not express endogenous Cav-1. Cav-1 was stably down-regulated via shRNA in androgen- independent PC3 and DU145 cells, which express abundant endogenous Cav-1. Alteration of Cav-1 expression in the three cell lines was confirmed by Western blot analysis (Figure 1 and S1). The cell lines differ in their expression of the cytoplasmic protein PTRF, which is necessary for caveola formation, thus allowing each combination of Cav-1 expression and caveola formation, as summarized in Table 1. Cav-1 down-regulation in DU145 resulted in reduced expression of PTRF. Cav-1 downregulation had no effect on PTRF expression in PC3 cells which lack PTRF. Cav-1 expression in LNCaP cells, which also lack PTRF, did not restore PTRF expression. It is important to note that in Cav-1-GFP LNCaP and in sh-Cont PC3, Cav-1 exists in a non-caveolar form because neither cell line expresses PTRF, whereas in S1 and S2 DU145, Cav-1 is able to form caveolae [34] since the cells express PTRF (Table 1).

\section{Effect of PCa Cav-1 on lymphatic endothelial cell (LEC) proliferation}

The effect of prostate cancer cell-conditioned medium on LEC proliferation was evaluated by the MTT assay. Ectopic expression of Cav-1 in LNCaP cells enhanced LEC proliferation significantly compared to cells exposed to the CM of control cells. Similarly, LECs exposed to the

A

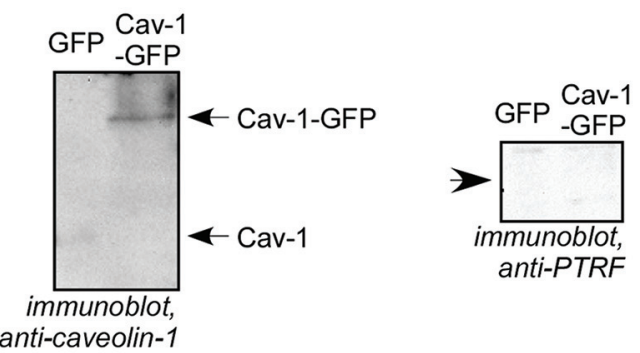

B
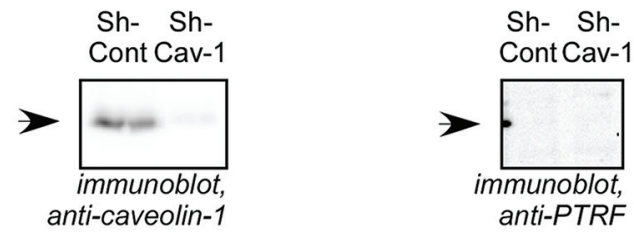

C
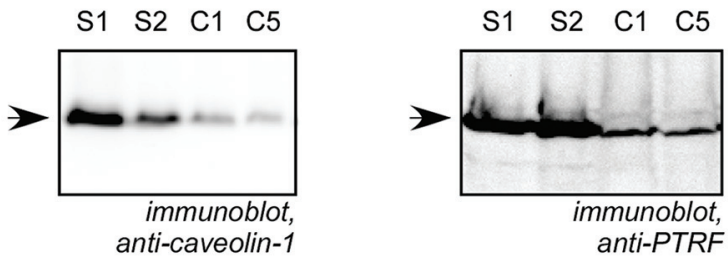

Figure 1: Characterization of Cav-1 and PTRF expression in prostate cancer cell lines. Cell lysates from prostate cancer cells were separated by SDS-PAGE and analysed by immunobloting with anti-caveolin-1 or anti-PTRF antibody as indicated. (A) LNCaP cells stably expressing GFP or Cav-1-GFP. (B) PC3 pooled cells stably transfected with non-targeting, control shRNA (sh-Cont) or with Cav-1 shRNA (sh-Cav-1). (C) DU145 cell clones stably transfected with scrambled shRNA(S1 and S2 clones) or with Cav-1 shRNA (C1 and C5 clones).

Table 1: Characteristics of the PCa cells with experimentally altered Cav-1 expression used in this study.

\begin{tabular}{|c|c|c|c|c|c|c|}
\hline \multirow[t]{2}{*}{ Transfection } & \multicolumn{2}{|c|}{$\mathrm{LNCaP}$} & \multicolumn{2}{|l|}{ PC3 } & \multicolumn{2}{|l|}{ DU145 } \\
\hline & GFP & Cav-1-GFP & Sh-Cont & Sh-Cav-1 & $\mathrm{S} 1, \mathrm{~S} 2$ & $\mathrm{C} 1, \mathrm{C} 5$ \\
\hline Caveolin-1 & - & + & + & $\searrow$ & + & $\searrow$ \\
\hline PTRF & - & - & - & - & + & $\searrow$ \\
\hline Caveolae & - & - & - & - & + & $\searrow \searrow$ \\
\hline & & $\begin{array}{l}\text { Non-caveolar } \\
\text { ectopic Cav-1 }\end{array}$ & $\begin{array}{c}\text { Non-caveolar } \\
\text { endogenous Cav-1 }\end{array}$ & & $\begin{array}{c}\text { Caveolar } \\
\text { endogenous Cav-1 }\end{array}$ & \\
\hline
\end{tabular}


conditioned medium of Cav-1-down-regulated PC3 cells showed significantly less proliferation than LECs treated with the CM of control cells expressing endogenous Cav-1. In contrast, down-regulation of Cav-1 expression in DU145 cells only marginally lowered LEC viability, and the change was not statistically significant (Figure 2). These results indicate that $\mathrm{Cav}-1$ expression in $\mathrm{LNCaP}$ and $\mathrm{PC} 3$, but not in DU145, promotes LEC proliferation.

\section{Effect of PCa Cav-1 on LEC migration}

We tested the ability of PCa cell-conditioned medium to promote chemokinesis by performing a scratch wound migration assay. LECs exposed to the conditioned medium of LNCaP cells expressing Cav-1 migrated significantly more than LECs exposed to CM of cells lacking Cav-1 (Figure $3 \mathrm{a}$ ). In addition, the attenuation of Cav-1 expression in PC3 cells led to significantly decreased LEC migration, while there was no significant difference in the random migration rate between LECs exposed to conditioned medium of control DU145 versus Cav-1-down-regulated DU145 cells (Figure 3a). To evaluate the impact of Cav-1 expression in PCa cells on LEC chemotaxis, a modified Boyden chamber migration assay was conducted using $\mathrm{PCa}$ cell-conditioned media in the lower wells. The number of migrated LECs was significantly higher when using the medium of Cav-1-expressing LNCaP cells than when using the medium of LNCaP devoid of Cav-1. Similarly, knockingdown Cav-1 expression in PC3 decreased the production of LEC-attracting factor(s) compared with control PC3 cells. However, there was no statistically significant effect of Cav-1 down-regulation in DU145 cells on directed LEC migration (Figure $3 \mathrm{~b}$ ). These results suggest that Cav-1 expression in LNCaP and PC3, but not DU145, promotes LEC migration.

\section{Effect of Cav-1 on differentiation of LEC into tube-like structures}

The consequences of Cav-1 expression in prostate cancer cells on their lymphangiogenic potential were further studied using LEC tube formation on MatrigelTM. LECs plated on Matrigel ${ }^{\mathrm{TM}}$ and exposed to conditioned medium of Cav-1-expressing LNCaP or PC3 cells formed significantly more tubes than LECs exposed to conditioned media of cells with lacking or down-regulated Cav-1 expression. In contrast, alteration of Cav-1 expression in DU145 cells did not significantly alter LEC differentiation into tubelike structures (Figure 4). These results show that Cav-1 expression in LNCaP and PC3 but not in DU145 promotes LEC differentiation.

\section{Effect of PCa Cav-1 expression on VEGF-A and VEGF-C production}

VEGF-A and -C are major regulators of lymphangiogenesis $[36,37]$. In order to unveil the mechanism by which Cav-1 regulates PCa lymphangiogenic potential, we measured the effect of modulating Cav-1 expression on the production of VEGF-A and VEGF-C in PCa cellconditioned media using ELISA. Overexpression of Cav-1 in LNCaP cells resulted in a significant increase in VEGF-A in the conditioned medium compared with the medium of control cells (Figure 5a). There was no detectable VEGF-C in LNCaP medium whether or not they expressed Cav-1 (not shown). Conditioned media of PC3 with down-regulated Cav-1 expression contained significantly less VEGF-A (Figure 5a) and VEGF-C (Figure 5b) compared with the medium of control PC3 cells. In DU145 cells, reduction of Cav-1 expression did not significant alter VEGF-A or VEGF-C production (Figure $5 \mathrm{a}, \mathrm{b}$ ). These results indicate that Cav-1 promotes expression of VEGF-A in LNCaP and PC3 but not in DU145, and expression of VEGF-C in PC3 but not in DU145.

To determine whether Cav-1 modulated expression of VEGF-A (in PC3 and LNCaP) and VEGF-C (in PC3) at a transcriptional level, we measured the mRNA levels of VEGF-A and VEGF-C using real time RT-qPCR (Figure 5c). The results revealed a significant increase in VEGF-A mRNA in Cav-1-expressing LNCaP cells $(p=0.0199)$ and a significant decrease of both VEGF-A $(p=0.0028)$ and VEGF-C $(p<0.0001)$ mRNAs in Cav-1 down-regulated PC3
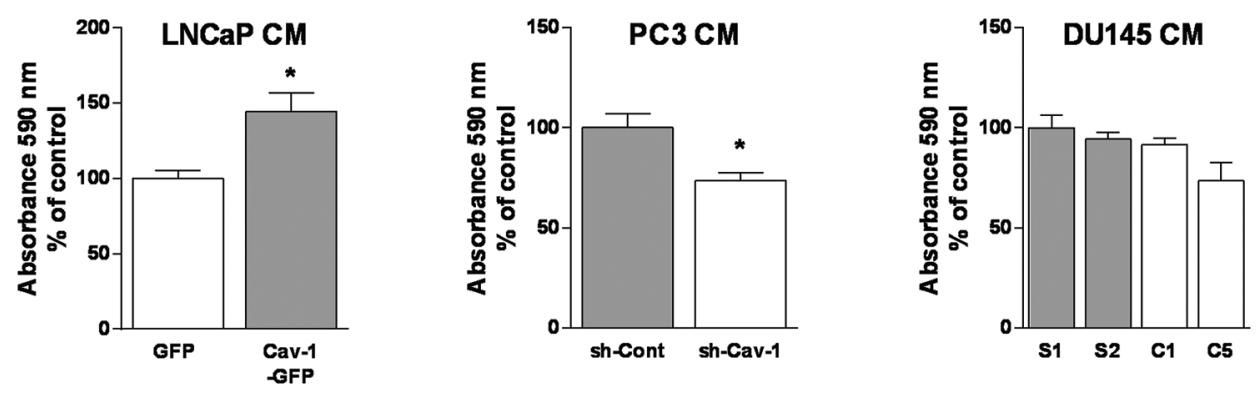

Figure 2: Effect of Cav-1 expression in prostate cancer cells on secretome-modulated LEC viability. LEC viability after $48 \mathrm{~h}$ exposure to prostate cancer cell-conditioned media was assessed using the MTT assay. Results are reported as percent of LEC viability compared to the control PCa cell conditioned medium and shown as mean \pm S.E.M. ( $\mathrm{n}=3$ separate experiments), ${ }^{*} p<0.05$. 
A

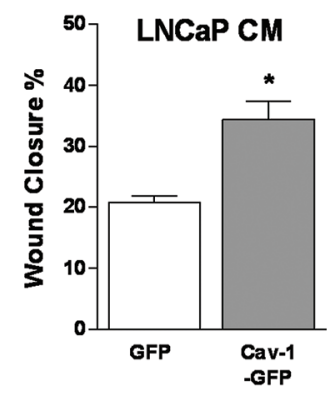

B

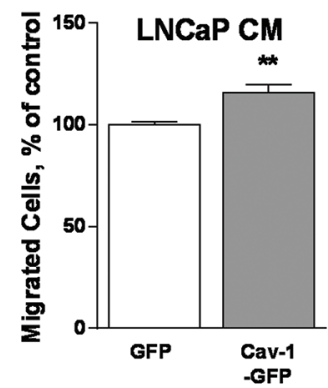

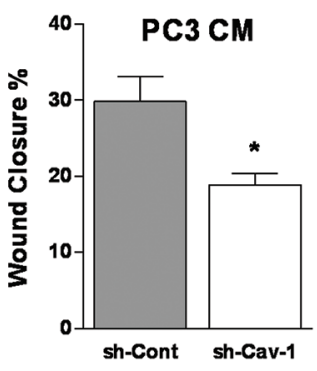
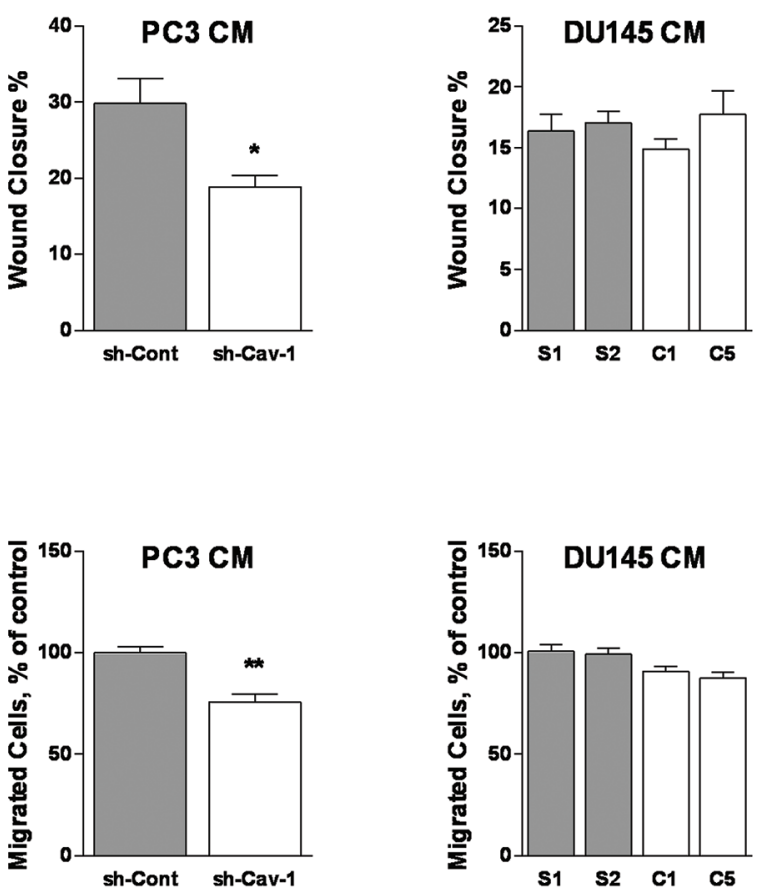

Figure 3: Effect of Cav-1 expression in prostate cancer cells on LEC chemotaxis and chemokinesis. (A) LEC ability to migrate randomly in two-dimension was tested using a wound healing assay during which cells were incubated in various prostate cancer cell-conditioned media for $6 \mathrm{~h}$. Results are reported as percent of wound closure and shown as mean \pm S.E.M. ( $\mathrm{n}=3$ separate experiments), $* p<0.05$. (B) LEC directional migration toward conditioned media from each prostate cancer cell line was assessed using the modified Boyden chamber assay. Results are reported as percent of the migration to conditioned medium of PCa control cells and shown as mean \pm S.E.M. ( $\mathrm{n}=3-5$ separate experiments), ${ }^{* *} p<0.01$.

cells (Figure 5c). In line with the ELISA results, VEGF-C mRNA was not detected in LNCaP cells (not shown).

\section{Cav-1 induction of LEC migration is mediated by VEGF-A}

To establish a causality link between the positive effects of Cav-1 expression in prostate cancer on VEGF-A, on the one hand, and functional in vitro assays indicating increased lymphangiogenesis, on the other hand, we tested whether VEGF-A antibody could neutralize the effect of Cav-1 expression on the pro-lymphangiogenic effects of the conditioned media of $\mathrm{PCa}$ cells. To that extent, we measured chemotaxis of LEC towards conditioned media from $\mathrm{PCa}$ cells added with anti-VEGF-A antibody (for cells that exhibited increased production of VEGF-A, namely LNCaP and PC3). The anti-VEGF-A neutralizing antibody reversed the effect of Cav-1 expression on PCa pro-lymphangiogenic potential: there was no statistically significant difference between sh-Cont and sh-Cav-1 medium or between GFP or Cav-1-GFP LNCaP medium in the presence of anti-VEGF-A (Figure 6), and there was statistically significant differences between IgG- and anti VEGF-A- added conditioned medium of Cav-1-expressing cells (sh-Cont PC3 or Cav-
1-GFP LNCaP). These results indicate that VEGF-A at least partly mediates the pro-lymphangiogenic effect of Cav-1 expression in PCa. We did not test whether adding anti-VEGF-C antibody to the conditioned medium would abolish the difference between LEC migration elicited by Cav-1 down-regulated and control PC 3 cells, because the concentration found in their conditioned medium $(\sim 0.75$ $\mathrm{ng} / \mathrm{ml}$ ) is below the minimal concentration of VEGF-C that elicits LEC chemotaxis in our model $(10 \mathrm{ng} / \mathrm{ml}$, data not shown). Together with the fact that Cav-1 expression alters the pro-lymphangiogenic potential of $\mathrm{LNCaP}$ cells despite their lack of VEGF-C expression, these results suggest that the effect of Cav-1 on PCa lymphangiogenesis in our experiments is likely not VEGF-C mediated.

\section{DISCUSSION}

The role of Cav-1 expression on PCa angiogenesis has been extensively studied. Immunohistochemistry of human prostate tumour specimens revealed that Cav-1 expression is associated with microvessel density and expression of the endothelial cell marker and angiogenesis signalling receptor, VEGF-R2 [19]. Orthotopic prostate tumour xenografts of Cav-1-secreting cells (RM-9) in Cav-1 gene-disrupted mice 
A
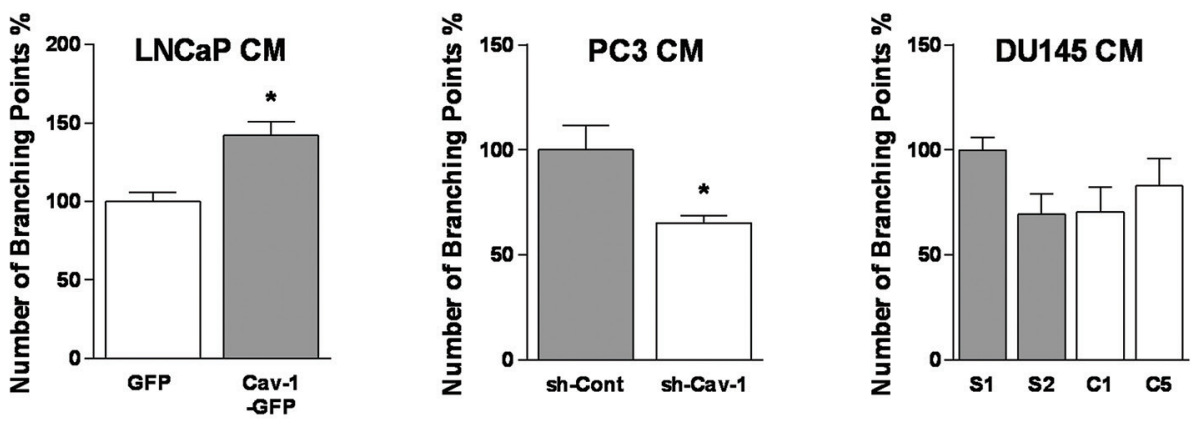

B

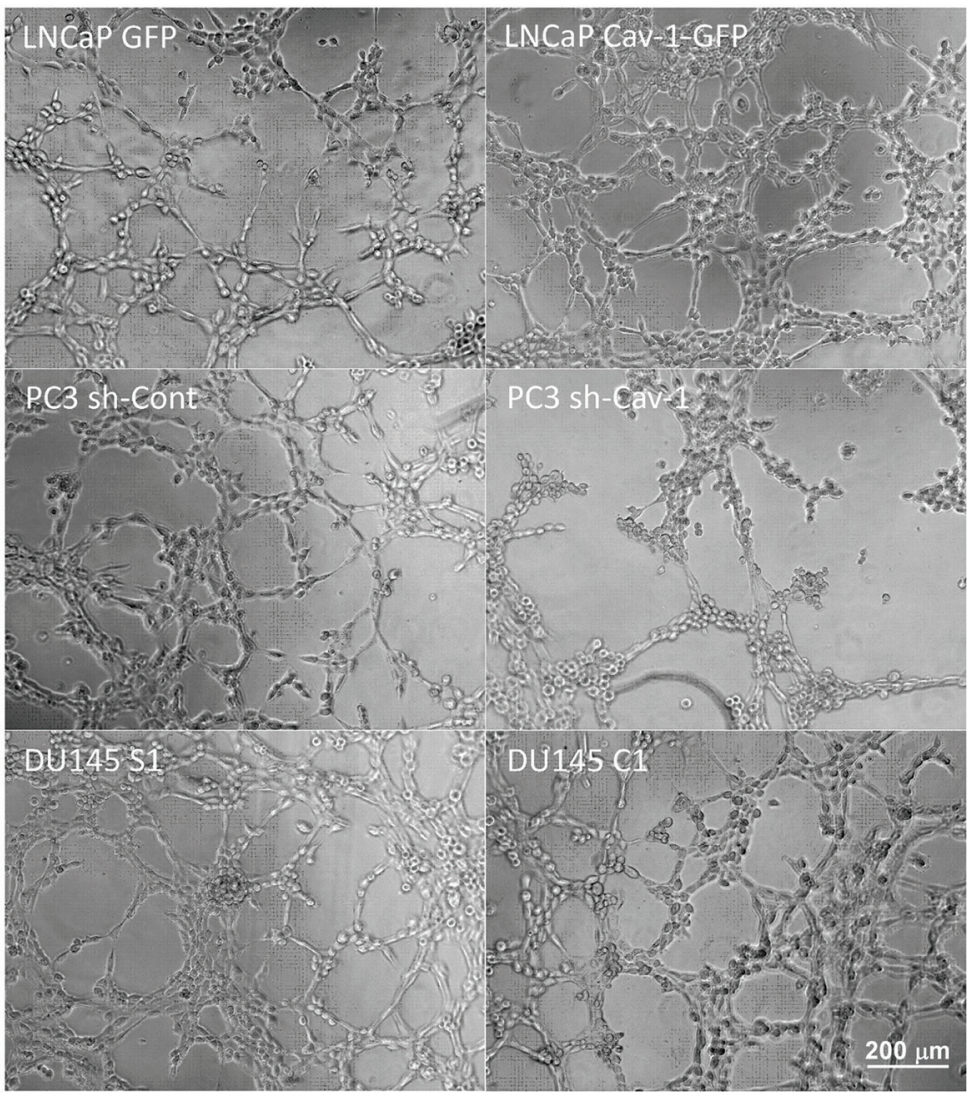

Figure 4: Effect of Cav-1 expression in prostate cancer cells on in vitro lymphangiogenesis. (A) LEC differentiation into tube-like structures was investigated by plating them on Matrigel ${ }^{\mathrm{TM}}$-pre-coated 96-well plates and exposing them to various prostate cancer cell-conditioned media for 4-6 $\mathrm{h}$. The number of branching points was quantified. Results are reported as percent of control PCa cell conditioned medium and shown as mean \pm S.E.M. ( $\mathrm{n}=3$ separate experiments), ${ }^{*} p<0.05$. (B) Representative micrographs of tubes formed by LEC exposed to PCa cell-conditioned media.

or their wild type counterparts revealed that the mean tumour weight and microvessel densities in $\mathrm{Cav}_{-1} \mathrm{I}^{(++)}$mice were higher than $\mathrm{Cav}-1^{(--)}$mice [23]. Interestingly, Cav-1 secreted by $\mathrm{PCa}$ cells modulates angiogenesis in vitro and in vivo; in a subcutaneous cancer model where the expression of Cav-1 in $\mathrm{LNCaP}$ cells can be induced by tetracyclin, microvessel density, tumour volume, lung metastasis [23] and expression of VEGF-A and TGF- $\beta 1$ [26] were significantly higher in Cav-1-expressing tumours compared with controls. In vitro, recombinant Cav-1 treatment of $\mathrm{Cav}^{-1^{(-)}}$endothelial cells 
A
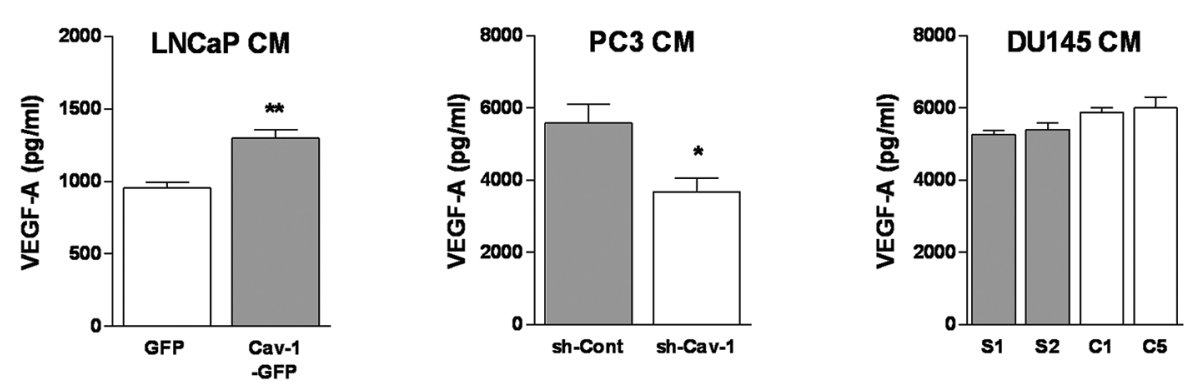

B
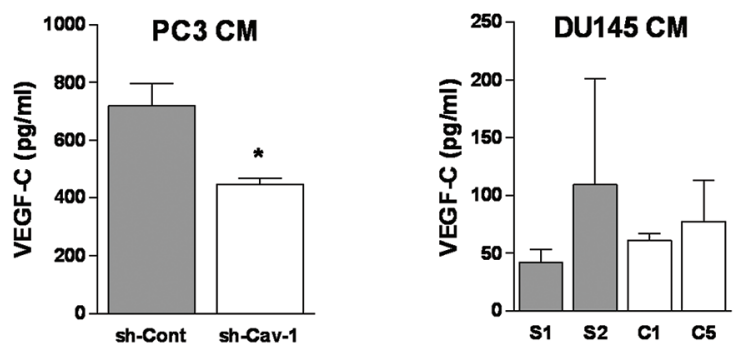

\section{C}
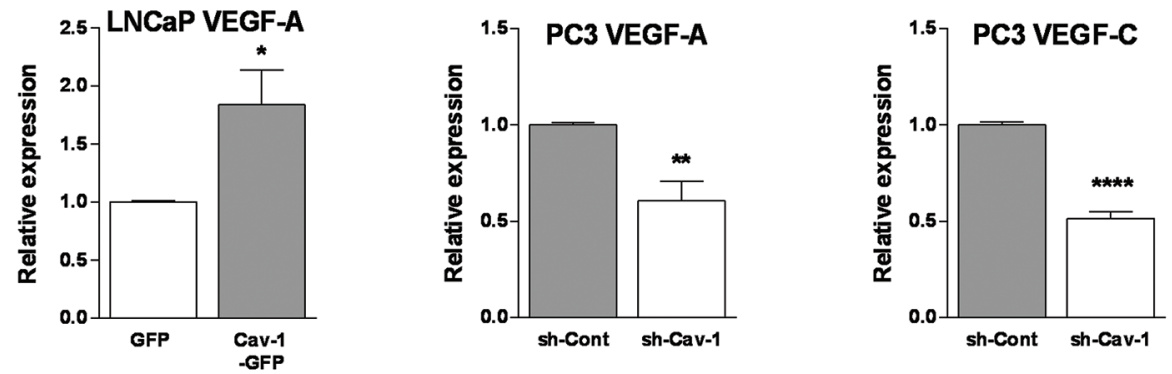

Figure 5: Effect of Cav-1 expression in prostate cancer cells on lymphangiogenesis-promoting growth factors. (A) Protein level of VEGF-A in prostate cancer cell-conditioned media was measured by ELISA. Results are presented as mean of growth factor concentration \pm S.E.M. ( $\mathrm{n}=3$ separate experiments), ${ }^{*} p<0.05$ and ${ }^{*} p<0.01$. (B) Protein level of VEGF-C in prostate cancer cell-conditioned media was measured by ELISA. Results are presented as mean of growth factor concentration \pm S.E.M. ( $\mathrm{n}=3$ separate experiments), ${ }^{*} p<0.05$. (C) mRNA level of VEGF-A and VEGF-C in prostate cancer cells was determined using real time RT-PCR. Relative expression compared to control cells is shown as mean \pm S.E.M. for 6 readings from three independent experiments. ${ }^{*} p<0.05,{ }^{* *} p<0.01$ and ${ }^{* * * *} p<0.0001$.

enhances nitric oxide production, cell migration and tubule formation through stimulation of the PI3K-Akt-eNOS [23], and VEGF/VEGFR2 signalling pathways [31]. Here, we report for the first time the promoting effect of Cav-1 on the ability of prostate cancer cells to elicit lymphangiogenesis.

Lymph nodes are a prime destination for prostate cancer metastatic cells. Three mechanisms have been suggested for prostate cancer lymphatic metastasis: a local extension of cancer cells to surrounding lymphatics (permeation), chemotactic invasion of the cancer cells toward cytokines expressed by the lymphatic vessels, and lymphangiogenesis [38]. To explore the mechanisms that underlie the pro-lymphangiogenic properties of $\mathrm{PCa} \mathrm{Cav}-1$, we studied the effect of modulating Cav-1 expression on the production of two master regulators of neovascularization, namely VEGF-A and -C.

In the two cell lines in which Cav-1 expression results in higher ability of the conditioned medium to elicit lymphangiogenesis in the in vitro functional assays we used, namely $\mathrm{LNCaP}$ and $\mathrm{PC} 3$ cells, we show associated changes in VEGF-A production in the conditioned medium. The effect of Cav-1 expression on VEGF-A expression in those cells was further seen at mRNA level. These results are in agreement with a previous study where transient down-regulation of Cav-1 in PC3 reduced the expression of VEGF-A and FGF2, while adenovirus-mediated expression of Cav-1 in LNCaP enhanced the expression of these growth factors [26]. In contrast, we did not detect a significant change 

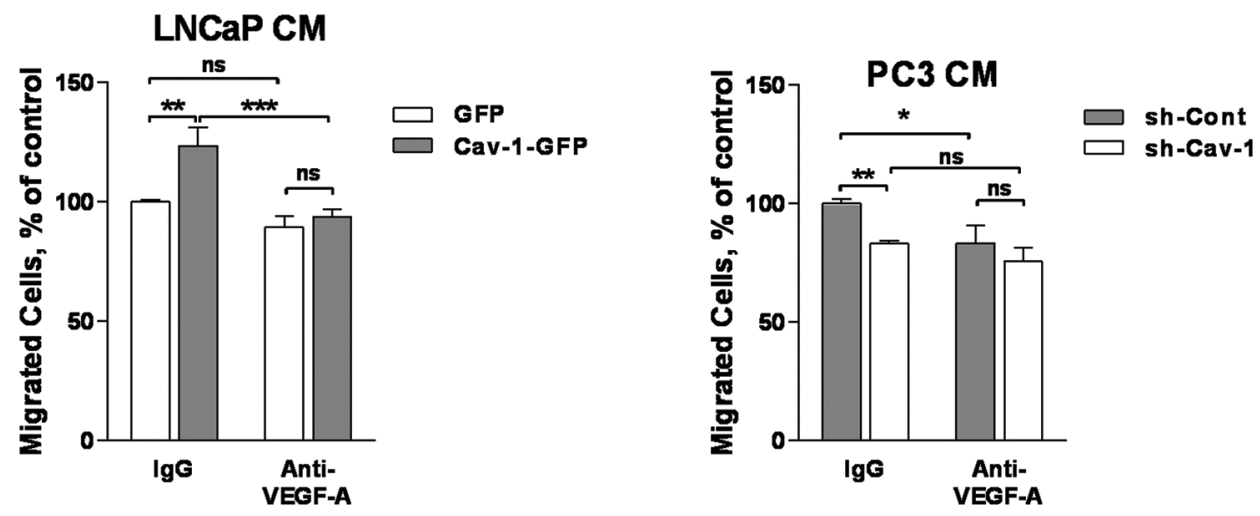

Figure 6: Effect of anti-VEGF-A antibody on prostate cancer cell-conditioned media-induced LEC migration. Chemotaxis towards PCa cell-conditioned media was tested using the Boyden chamber assay in the presence or absence of anti-VEGF-A antibody as indicated. Results are reported as percent of the migration to control cell conditioned medium and shown as mean \pm S.E.M. ( $n=3$ separate experiment), ${ }^{*} p<0.05, * * p<0.01, * * * p<0.001$, ns no statistical significance.

in VEGF-A in the conditioned medium of DU145 when Cav-1 expression was altered, and this corroborates the lack of associated outcomes in the functional assays. Importantly, we established a causality link between modulation of VEGF-A expression in PC3 or LNCaP, and promotion of lymphangiogenesis by performing the chemotaxis assay of LEC in the presence of neutralizing anti-VEGF-A antibody.

LNCaP did not express any detectable VEGF-C, either in the conditioned medium or at mRNA level. However in PC3 cells, Cav-1 downregulation was associated with a decrease in VEGF-C transcription and expression. Because the highest concentration of VEGF-C in the conditioned medium of $\mathrm{PC} 3$ cells is unable to elicit LEC transmigration in our model, and the anti-VEGF-A completely abolished the difference of migration between conditioned media of Cav-1-expressing and -down-regulated cells, we suggest that the effect of $\mathrm{PCa}$ Cav-1 on lymphangiogenesis is mediated by the panangiogenic factor VEGF-A. VEGF-A is best known as a potent angiogenesis stimulator. Although VEGF-A has no role in lymphangiogenesis during embryogenesis, its involvement in tumour lymphangiogenesis and lymphatic metastasis is documented [39-43]. It was reported by Garmy-Susini et al. that both VEGF-A and VEGF-C induce integrin $\alpha 1 \beta 4$ expression by lymphatic vessels during lymphangiogenesis [44]. The same group later showed that VEGF-C activation of integrin $\alpha 1 \beta 4$ in lymphatic endothelial cells is PI3K $\alpha$-mediated [45]. While we have not examined the ability of VEGF-A to activate PI $3 \mathrm{~K} \alpha$ and $\alpha 1 \beta 4$, the ability of VEGF-A to increase phosphorylation of the PI3K downstream signalling molecule Akt, in the same cell line that we have used throughout this study, is documented [46].

Our study employs loss or gain of Cav-1 expression in PC 3 and LNCaP cells, respectively, and suggests that in these two cell lines Cav-1 promotes lymphangiogenic potential. However, the down-regulation of Cav-1 in DU145 did not seem to alter their lymphangiogenic potential. These cell lines differ in their expression of PTRF, which is absent in PC3 and LNCaP but abundant in DU145 (Table 1). Both
Cav-1 and PTRF are essential for caveola formation [32]. In most cell types and tissues, Cav-1 expression matches PTRF expression, a phenomenon attributed to co-regulation at the transcriptional level and/or to the ability of PTRF to rescue Cav-1 from lysosomal degradation [32, 47]. However, in prostate cancer the balance between the two proteins is lost as indicated by two studies of prostate cancer tissues $[35,48]$. In PC3 cells, which recapitulate the abundance of Cav-1 and absence of PTRF seen in clinical samples, caveolae are absent, and non-caveolar Cav-1 can be detected on flat plasma membrane [32]. Distinct pools of Cav-1 therefore need to be taken into account, which can undergo different fates (e.g. lysosomal degradation, inclusion in prostasomes) and play distinct roles, depending on whether or not PTRF is present $[11,32,49]$. Ectopic expression of PTRF in PC3 restores caveola formation and sequestrates Cav-1 in caveolae [32]. It has been suggested that in prostate cancer, the tumour-promoting roles of Cav-1 are due to a non-caveolar form of the protein [11,33-35]. In the present study, we show that non-caveolar Cav-1 (in PC3 and $\mathrm{LNCaP}$ ) promotes lymphangiogenesis while caveolar Cav-1 (in DU145) has no effect. We have previously reported that ectopic expression of PTRF in PC3 cells results in an increased expression of Cav-1 [34], and yet reduced $\mathrm{PCa}$ cell lymphangiogenic and angiogenic potential, tumour growth and metastasis in vitro and in vivo $[34,35]$. The effect of PTRF on lymphangiogenesis was seen whether or not the cell expressed Cav-1. Therefore, overexpression of non-caveolar Cav-1 and a lack of PTRF both contribute to enhanced lymphangiogenesis in $\mathrm{PCa}$.

\section{MATERIALS AND METHODS}

\section{Reagents}

RPMI-1640, DMEM, foetal bovine serum (FBS), trypsin, penicillin/streptomycin solution, G418 sulfate, 
sodium pyruvate and glutamine were obtained from Invitrogen (Life Technologies, VIC, Australia). Non-essential amino acids (NEAA) were from Lonza (VIC, Australia). IGEPAL, leupeptin, aprotinin, 3-(4,5-dimethylthiazol-2yl)-2,5-diphenyltetrazolium bromide (MTT), hematoxylin, rat tail collagen and nitrocellulose membranes were purchased from Sigma-Aldrich (NSW, Australia). Dimethyl sulfoxide (DMSO) was from Chem-supply (SA, Australia). Immobilon polyvinyldifluoride (PVDF) membranes were from Fisher Scientific (VIC, Australia). Random primers and Recombinant RNasin ${ }^{\circledR}$ Ribonuclease inhibitors were obtained from Promega (NSW, Australia). Rabbit polyclonal anti-caveolin-1 was from BD Biosciences (NSW, Australia), anti-PTRF from ProteinTech (NSW, Australia), anti-VEGF-A was from R\&D (BioScientific, NSW, Australia), mouse monoclonal antibody to GAPDH was from Acris (Life Research, NSW, Australia).

\section{Cell culture}

The expression of Cav-1 was experimentally altered in three human prostate adenocarcinoma cell lines, namely DU145, LNCaP and PC3. LNCaP clones expressing GFP-tagged Cav-1 (LNCaP-Cav-1-GFP) or control cells expressing GFP alone (LNCaP-GFP) were generated by transfection using transpass D2 reagent (New England Biolabs, QLD, Australia) and G418 selection. Stable downregulation of Cav-1 expression in PC3 was previously described [33]. Two clones each of Cav-1 down-regulated cells (DU145-C1 and DU145-C5) and control shRNAtransfected cells (DU145-S1 and DU145-S2) were generated and used throughout this study.

Cells were cultured in RPMI-1640 medium supplemented with 100 i.u. $/ \mathrm{ml}$ penicillin, $100 \mu \mathrm{g} / \mathrm{ml}$ streptomycin, $375 \mu \mathrm{g} / \mathrm{ml} \mathrm{G} 418$ sulfate and 5\% (v/v) FBS (PC3) or 10\% (v/v) FBS (DU145 and LNCaP cells). The cells were cultured in $5 \% \mathrm{CO} 2$ in a humidified atmosphere at $37^{\circ} \mathrm{C}$. Lymphatic endothelial cells (LECs) were previously isolated from mice expressing temperature-sensitive SV40 large $\mathrm{T}\left(H-2 K^{b}\right.$-tsA58) [46]. LECs were propagated in DMEM medium supplemented with $10 \%$ (v/v) FBS, 100 i.u. $/ \mathrm{ml}$ penicillin, $100 \mu \mathrm{g} / \mathrm{ml}$ streptomycin, $1 \%$ sodium pyruvate, $1 \%$ glutamine and $1 \%$ non-essential amino-acids. LECs were maintained in $8 \% \mathrm{CO} 2$ in a humidified atmosphere at $33^{\circ} \mathrm{C}$, and transferred to $37^{\circ} \mathrm{C}, 5 \% \mathrm{CO} 2$ for $72 \mathrm{~h}$ prior to experiments.

\section{Conditioned medium preparation}

Prostate cancer cells were grown in $10 \mathrm{~cm}$ dishes until $70 \%$ confluent and washed twice with PBS. Cells were then incubated with $5 \mathrm{ml}$ serum-free medium for 48 h. Subsequently, the conditioned medium was collected and cell debris removed by centrifugation at $400 \mathrm{x}$ g for $5 \mathrm{~min}$. The conditioned media were stored at $-20^{\circ} \mathrm{C}$ until further use.

\section{Western blot analysis}

Prostate cancer cell lysates were prepared as described previously [34]. Equal amounts of proteins were resolved using SDS-PAGE electrophoresis and transferred to PVDF membranes. The blots were blocked with $5 \%(\mathrm{w} / \mathrm{v})$ skim milk in phosphate buffer saline (PBS) for $1 \mathrm{~h}$ at room temperature and probed with rabbit anti-caveolin- $1(0.25 \mu \mathrm{g} / \mathrm{ml})$, rabbit anti-PTRF $(1.38 \mu \mathrm{g} / \mathrm{ml})$ or mouse anti-GAPDH $(0.1 \mu \mathrm{g} / \mathrm{ml})$ antibody followed by peroxidase-conjugated donkey anti-rabbit or sheep anti-mouse secondary antibody (GE Healthcare, NSW, Australia). Subsequent visualization was conducted using SuperSignal ${ }^{\circledR}$ West Dura extended duration substrate (Thermo Fisher Scientific, VIC, Australia) and VersaDoc TM 4000 imaging system.

\section{Cell viability assay}

The effect of prostate cancer cell conditioned medium on LEC proliferation was assessed using the MTT assay. Briefly, $1 \times 10^{4}$ cells per well were seeded in a 96-well plate. After overnight incubation, cells were washed twice with PBS and $100 \mu \mathrm{l}$ of PCa cell-conditioned medium was added in triplicate wells. After $48 \mathrm{~h}$ of incubation, the medium was aspirated and replaced by $100 \mu \mathrm{l}$ medium containing $0.5 \mathrm{mg} / \mathrm{ml} \mathrm{MTT}$. The plates were further incubated for $3 \mathrm{~h}$. Subsequently, the MTT solution was aspirated, the formazan crystals were solubilized by DMSO and the absorbance at $590 \mathrm{~nm}$ was measured. The results are presented as percent of viability of LEC exposed to control cell conditioned media.

\section{Chemokinesis measurement}

A wound healing assay was conducted as described previously [50]. LECs were seeded in 24 well-plates until formation of a confluent monolayer. The middle of the wells was then scraped with a 20-200 $\mu$ l micropipette tip to create a wound. Cells were washed twice with PBS and placed in prostate cancer cell-conditioned medium. The width of each wound was documented promptly after wound creation $(0 \mathrm{~h})$ and after $6 \mathrm{~h}$ of incubation with the conditioned media. The wound width was measured using Image J software (National Institutes of Health, Bethesda, MD). The percentage of wound closure was calculated [34]. The results are presented as percent of wound closure.

\section{Chemotaxis assay}

Directional migration was assessed using a 48-well modified Boyden chamber assay. Prostate cancer CM was added into the lower compartment of the chambers. The wells were covered by an $8 \mu \mathrm{m}$ pore polycarbonate membrane pre-coated with rat tail collagen type $1(100 \mu \mathrm{g} / \mathrm{ml}$ in $0.2 \mathrm{~N}$ acetic acid) and equilibrated at $37^{\circ} \mathrm{C}$. The upper wells were then filled with $30 \times 10^{4}$ cells $/ \mathrm{ml}$ in serum free medium. After 
$4 \mathrm{~h}$ incubation, the membranes were collected, washed with PBS and the non-migrated cells were scraped from the upper face. The membranes were fixed in $4 \%$ paraformaldehyde for $30 \mathrm{~min}$, stained with hematoxylin overnight and mounted using permount mounting medium. The number of migrated cells was counted microscopically [51]. Results are reported as percent of the migration of LEC towards conditioned media of control PCa cells.

\section{Tube formation assay}

Matrigel $^{\text {TM }}$ (Life Technologies, VIC, Australia), a tumour-derived gelatinous protein mixture rich in growth factors and basement membrane components, able to promote blood and lymphatic endothelial cell differentiation $[52,53]$ was thawed at $4{ }^{\circ} \mathrm{C}$ overnight. Fifty $\mu$ l of Matrigel ${ }^{\mathrm{TM}}$ were pipetted into the wells of a 96 well-plate and incubated at $37{ }^{\circ} \mathrm{C}$ for $45 \mathrm{~min}$ for polymerization. LECs in $100 \mu \mathrm{L}$ of prostate cancer cell-conditioned medium were added to the pre-coated wells. After $4-6 \mathrm{~h}$ of incubation at $37^{\circ} \mathrm{C}$, tube-like structures were imaged and the number of branching points was counted [34, 54]. The number of branching points is presented as a percent of control cell-conditioned medium.

\section{Determination of VEGF-A and VEGF-C concentration in PCa cell conditioned media}

VEGF-A and VEGF-C concentrations were determined using RayBio ${ }^{\circledR}$ Human ELISA kits (BioScientific, NSW, Australia) as per manufacturer's instructions. At the time of the quantification a calibration curve of VEGF-A and VEGF-C standards was prepared. The concentration of the proteins in samples was calculated using the log-log regression equation of the best fit line of the standard calibration curve. Results are presented as mean concentration of the protein.

\section{RNA isolation and quantitative real-time reverse transcriptase polymerase chain reaction (RT-PCR)}

Total RNA was isolated using Purelink RNA mini kit ${ }^{\circledR}$ (Life Technologies, VIC, Australia) from 70\% confluent prostate cancer cells. For RNA quantification, absorbance values $(260,280 \mathrm{~nm})$ were measured using Thermo Fisher NanoDrop. Complementary DNA (cDNA) was synthesized from $2 \mu \mathrm{g}$ total RNA using Omniscript RT kit (Qiagen, Victoria, Australia) in a final volume of $20 \mu \mathrm{l}$ using random primers according to the supplier's instructions.

The cDNA was amplified using TaqMan Universal PCR Master Mix containing AmpliTaq Gold ${ }^{\circledR}$ DNA Polymerase, dNTPs with dUTP, Passive Reference 1 and optimized buffer components. The amplification was carried out through a StepOnePlus Real Time PCR System (Applied Biosystems) using universal cycling conditions $\left(95^{\circ} \mathrm{C}, 10 \mathrm{~min}\right.$ then $95^{\circ} \mathrm{C}$, $15 \mathrm{sec}$; and $60^{\circ} \mathrm{C}, 1 \mathrm{~min}$ for 40 cycles). Gene Expression Assays (FAM $\left.{ }^{\mathrm{TM}}-\mathrm{MGB}, 20 \mathrm{X}\right)$ for human VEGF-A
(Hs01052961_m1) and VEGF-C (Hs00153458_m1) were obtained from Life Technologies (VIC, Australia).

Relative quantification was done with reference to $18 \mathrm{~S}$ ribosomal RNA (18S rRNA) and analysed using the comparative $2-\Delta \Delta \mathrm{CT}$ method [55]. Results are presented as relative gene expression compared to control.

\section{Statistical analysis}

Results are reported as mean \pm S.E.M. Statistical analysis was performed using GraphPad Prism (V6.0 for Windows). $p$ values $<0.05$ were considered significant.

\section{CONCLUSION}

This study shows that expression of non-caveolar Cav-1 by PCa cells promotes lymphangiogenesis and suggests a mechanism mediated by the panangiogenesis regulator VEGF-A. Prostate cancer lymphatic metastasis is an early hallmark of disease progression, suggesting that this novel finding could be exploited to develop novel therapeutic strategies for prostate cancer.

\section{CONFLICT OF INTEREST}

The authors declare no conflict of interest.

\section{GRANT SUPPORT}

M.O.P. and M.F. acknowledge Australia Research Council (ARC) Discovery Project DP140100485. M.M.H. acknowledges the support from Prostate Cancer Foundation of Australia Young Investigator Grant ID YI14. R.G.P. is funded by a fellowship and grants (569542, 1037320, 1045092) from the National Health and Medical Research Council of Australia.

\section{REFERENCES}

1. Cai T, Nesi G, Tinacci G, Giubilei G, Gavazzi A, Mondaini N, Zini E and Bartoletti R. Clinical importance of lymph node density in predicting outcome of prostate cancer patients. J Surg Res. 2011; 167(2):267-272.

2. Tsurusaki T, Kanda S, Sakai H, Kanetake H, Saito Y, Alitalo K and Koji T. Vascular endothelial growth factor-C expression in human prostatic carcinoma and its relationship to lymph node metastasis. Br J Cancer. 1999; 80(1-2):309-313.

3. Jennbacken $\mathrm{K}$, Vallbo $\mathrm{C}$, Wang $\mathrm{W}$ and Damber J-E. Expression of vascular endothelial growth factor C (VEGF-C) and VEGF receptor-3 in human prostate cancer is associated with regional lymph node metastasis. The Prostate. 2005; 65(2):110-116.

4. Brakenhielm E, Burton JB, Johnson M, Chavarria N, Morizono K, Chen I, Alitalo $\mathrm{K}$ and $\mathrm{Wu} \mathrm{L}$. Modulating 
metastasis by a lymphangiogenic switch in prostate cancer. International journal of cancer. 2007; 121(10):2153-2161.

5. Yang J, Wu HF, Qian LX, Zhang W, Hua LX, Yu ML, Wang Z, $\mathrm{Xu} Z \mathrm{ZQ}$, Sui YG and Wang XR. Increased expressions of vascular endothelial growth factor (VEGF), VEGF-C and VEGF receptor-3 in prostate cancer tissue are associated with tumor progression. Asian journal of andrology. 2006; 8(2):169-175.

6. West AF, O'Donnell M, Charlton RG, Neal DE and Leung HY. Correlation of vascular endothelial growth factor expression with fibroblast growth factor- 8 expression and clinico-pathologic parameters in human prostate cancer. $\mathrm{Br}$ J Cancer. 2001; 85(4):576-583.

7. Stacker SA, Williams SP, Karnezis T, Shayan R, Fox SB and Achen MG. Lymphangiogenesis and lymphatic vessel remodelling in cancer. Nature Reviews Cancer. 2014; 14(3):159-172.

8. Baldwin ME, Tester AM, Phelan D and Klupacs R. The novel therapeutic monoclonal antibody VGX-100 neutralises VEGF-C and inhibits tumor growth and metastasis in subcutaneous and orthotopic models of human cancer. Cancer Res. 2011; 71(8 Supplement):LB-284.

9. Lin J, Lalani AS, Harding TC, Gonzalez M, Wu WW, Luan B, Tu GH, Koprivnikar K, VanRoey MJ, He Y, Alitalo K and Jooss K. Inhibition of lymphogenous metastasis using adeno-associated virus-mediated gene transfer of a soluble VEGFR-3 decoy receptor. Cancer Res. 2005; 65(15):69016909.

10. Burton JB, Priceman SJ, Sung JL, Brakenhielm E, An DS, Pytowski B, Alitalo K and Wu L. Suppression of prostate cancer nodal and systemic metastasis by blockade of the lymphangiogenic axis. Cancer Res. 2008; 68(19):7828-7837.

11. Nassar ZD, Hill MM, Parton RG and Parat M-O. Caveolaforming proteins caveolin-1 and PTRF in prostate cancer. Nat Rev Urol. 2013; 10(9):529-536.

12. Parat MO and Riggins GJ. Caveolin-1, caveolae, and glioblastoma. Neuro-oncology. 2012; 14(6):679-688.

13. Sainz-Jaspeado M, Martin-Liberal J, Lagares-Tena L, MateoLozano S, Garcia del Muro X and Tirado OM. Caveolin-1 in sarcomas: friend or foe? Oncotarget. 2011; 2(4):305-312.

14. Huertas-Martinez J, Rello-Varona S, Herrero-Martin D, Barrau I, Garcia-Monclus S, Sainz-Jaspeado M, LagaresTena L, Nunez-Alvarez Y, Mateo-Lozano S, Mora J, Roma J, Toran N, Moran S, Lopez-Alemany R, Gallego S, Esteller M, et al. Caveolin-1 is down-regulated in alveolar rhabdomyosarcomas and negatively regulates tumor growth. Oncotarget. 2014; 5(20):9744-9755.

15. Yamaguchi H and Oikawa T. Membrane lipids in invadopodia and podosomes: key structures for cancer invasion and metastasis. Oncotarget. 2010; 1(5):320-328.

16. Satoh T, Yang G, Egawa S, Addai J, Frolov A, Kuwao S, Timme TL, Baba S and Thompson TC. Caveolin-1 expression is a predictor of recurrence-free survival in pT2N0 prostate carcinoma diagnosed in Japanese patients. Cancer. 2003; 97(5):1225-1233.

17. Yang G, Truong LD, Wheeler TM and Thompson TC. Caveolin-1 expression in clinically confined human prostate cancer. Cancer Res. 1999; 59(22):5719.

18. Tahir SA, Yang G, Ebara S, Timme TL, Satoh T, Li L,
Goltsov A, Ittmann M, Morrisett JD and Thompson TC. Secreted caveolin-1 stimulates cell survival/clonal growth and contributes to metastasis in androgen-insensitive prostate cancer. Cancer Res. 2001; 61(10):3882-3885.

19. Yang G, Addai J, Wheeler TM, Frolov A, Miles BJ, Kadmon D and Thompson TC. Correlative evidence that prostate cancer cell-derived caveolin-1 mediates angiogenesis. Hum Pathol. 2007; 38(11):1688-1695.

20. Karam JA, Lotan Y, Roehrborn CG, Ashfaq R, Karakiewicz PI and Shariat SF. Caveolin-1 overexpression is associated with aggressive prostate cancer recurrence. The Prostate. 2007; 67(6):614-622.

21. Li L, Yang G, Ebara S, Satoh T, Nasu Y, Timme TL, Ren C, Wang J, Tahir SA and Thompson TC. Caveolin-1 mediates testosterone-stimulated survival/clonal growth and promotes metastatic activities in prostate cancer cells. Cancer Res. 2001; 61(11):4386.

22. Williams TM, Hassan GS, Li J, Cohen AW, Medina F, Frank PG, Pestell RG, Di Vizio D, Loda M and Lisanti MP. Caveolin-1 promotes tumor progression in an autochthonous mouse model of prostate cancer. J Biol Chem. 2005; 280(26):25134.

23. Tahir SA, Yang G, Goltsov AA, Watanabe M, Tabata K, Addai J, Fattah eMA, Kadmon D and Thompson TC. Tumor cell-secreted caveolin-1 has proangiogenic activities in prostate cancer. Cancer Res. 2008; 68(3):731-739.

24. Bartz R, Zhou J, Hsieh J-T, Ying Y, Li W and Liu P. Caveolin-1 secreting LNCaP cells induce tumor growth of caveolin-1 negative $\mathrm{LNCaP}$ cells in vivo. International journal of cancer. 2008; 122(3):520-525.

25. Watanabe M, Yang G, Cao G, Tahir SA, Naruishi K, Tabata K-i, Fattah EA, Rajagopalan K, Timme TL, Park S, Kurosaka S, Edamura K, Tanimoto R, Demayo FJ, Goltsov AA and Thompson TC. Functional analysis of secreted caveolin-1 in mouse models of prostate cancer progression. Molecular Cancer Research. 2009; 7(9):14461455 .

26. Li L, Ren C, Yang G, Goltsov AA, Tabata K-i and Thompson TC. Caveolin-1 Promotes Autoregulatory, AktMediated Induction of Cancer-Promoting Growth Factors in Prostate Cancer Cells. Molecular Cancer Research. 2009; 7(11):1781-1791.

27. Moon H, Ruelcke JE, Choi E, Sharpe LJ, Nassar ZD, Bielefeldt-Ohmann H, Parat MO, Shah A, Francois M, Inder KL, Brown AJ, Russell PJ, Parton RG and Hill MM. Diet-induced hypercholesterolemia promotes androgenindependent prostate cancer metastasis via IQGAP1 and caveolin-1. Oncotarget. 2015; 6(10):7438-7453.

28. Tahir SA, Frolov A, Hayes TG, Mims MP, Miles BJ, Lerner SP, Wheeler TM, Ayala G, Thompson TC and Kadmon D. Preoperative serum caveolin-1 as a prognostic marker for recurrence in a radical prostatectomy cohort. Clin Cancer Res. 2006; 12(16):4872-4875.

29. Gumulec J, Sochor J, Hlavna M, Sztalmachova M, Krizkova S, Babula P, Hrabec R, Rovny A, Adam V, Eckschlager T, Kizek R and Masarik M. Caveolin-1 as a potential high-risk prostate cancer biomarker. Oncol Rep. 2012; 27(3):831-841.

30. Li L, Ren $\mathrm{CH}$, Tahir SA, Ren $\mathrm{C}$ and Thompson TC. 
Caveolin-1 Maintains Activated Akt in Prostate Cancer Cells through Scaffolding Domain Binding Site Interactions with and Inhibition of Serine/Threonine Protein Phosphatases PP1 and PP2A. Mol Cell Biol. 2003; 23(24):9389-9404.

31. Tahir SA, Park S and Thompson TC. Caveolin-1 regulates VEGF-stimulated angiogenic activities in prostate cancer and endothelial cells. Cancer Biology \& Therapy. 2009; 8(23):2286.

32. Hill MM, Bastiani M, Luetterforst $R$, Kirkham $M$, Kirkham A, Nixon SJ, Walser P, Abankwa D, Oorschot VM, Martin S, Hancock JF and Parton RG. PTRF-Cavin, a conserved cytoplasmic protein required for caveola formation and function. Cell. 2008; 132(1):113-124.

33. Hill MM, Daud NH, Aung CS, Loo D, Martin S, Murphy S, Black DM, Barry R, Simpson F, Liu L, Pilch PF, Hancock JF, Parat M-O and Parton RG. Co-regulation of cell polarization and migration by caveolar proteins PTRF/Cavin-1 and caveolin-1. PloS one. 2012; 7(8):e43041.

34. Nassar ZD, Moon H, Duong T, Neo L, Hill MM, Francois M, Parton RG and Parat M-O. PTRF/Cavin-1 decreases prostate cancer angiogenesis and lymphangiogenesis. Oncotarget. 2013; 4(10):1844.

35. Moon H, Lee CS, Inder KL, Sharma S, Choi E, Black DM, Le Cao KA, Winterford C, Coward JI, Ling MT, Craik DJ, Parton RG, Russell PJ and Hill MM. PTRF/cavin-1 neutralizes non-caveolar caveolin-1 microdomains in prostate cancer. Oncogene. 2014; 33(27):3561-3570.

36. Zheng W, Aspelund A and Alitalo K. Lymphangiogenic factors, mechanisms, and applications. J Clin Invest. 2014; 124(3):878-887.

37. Chang Y-W, Su C-M, Su Y-H, Ho Y-S, Lai H-H, Chen H-A, Kuo M-L, Hung W-C, Chen Y-W, Wu C-H, Chen P-S and $\mathrm{Su}$ J-L. Novel peptides suppress VEGFR-3 activity and antagonize VEGFR-3-mediated oncogenic effects. Oncotarget. 2014; 5(11):3823-3835.

38. Datta K, Muders M, Zhang H and Tindall DJ. Mechanism of lymph node metastasis in prostate cancer. Future oncology (London, England). 2010; 6(5):823-836.

39. Hirakawa S, Kodama S, Kunstfeld R, Kajiya K, Brown LF and Detmar M. VEGF-A induces tumor and sentinel lymph node lymphangiogenesis and promotes lymphatic metastasis. J Exp Med. 2005; 201(7):1089-1099.

40. Björndahl MA, Cao R, Burton JB, Brakenhielm E, Religa P, Galter D, Wu L and Cao Y. Vascular endothelial growth factor-A promotes peritumoral lymphangiogenesis and lymphatic metastasis. Cancer Res. 2005; 65(20):9261-9268.

41. Nagy JA, Vasile E, Feng D, Sundberg C, Brown LF, Detmar MJ, Lawitts JA, Benjamin L, Tan X and Manseau EJ. Vascular permeability factor/vascular endothelial growth factor induces lymphangiogenesis as well as angiogenesis. J Exp Med. 2002; 196(11):1497-1506.

42. Chen HM, Tsai $\mathrm{CH}$ and Hung WC. Foretinib inhibits angiogenesis, lymphangiogenesis and tumor growth of pancreatic cancer in vivo by decreasing VEGFR-2/3 and TIE-2 signaling. Oncotarget. 2015:In Press.
43. Karnezis T, Shayan R, Fox S, Achen MG and Stacker SA. The connection between lymphangiogenic signalling and prostaglandin biology: A missing link in the metastatic pathway. Oncotarget. 2012; 3(8):890-903.

44. Garmy-Susini B, Avraamides CJ, Schmid MC, Foubert P, Ellies LG, Barnes L, Feral C, Papayannopoulou T, Lowy A, Blair SL, Cheresh D, Ginsberg $M$ and Varner JA. Integrin $\alpha 4 \beta 1$ signaling is required for lymphangiogenesis and tumor metastasis. Cancer research. 2010; 70(8):3042-3051.

45. Garmy-Susini B, Avraamides CJ, Desgrosellier JS, Schmid MC, Foubert P, Ellies LG, Lowy AM, Blair SL, Vandenberg SR, Datnow B, Wang HY, Cheresh DA and Varner J. PI3Kalpha activates integrin alpha4beta1 to establish a metastatic niche in lymph nodes. Proc Natl Acad Sci U S A. 2013; 110(22):9042-9047.

46. Rebhun RB, Langley RR, Yokoi K, Fan D, Gershenwald JE and Fidler IJ. Targeting receptor tyrosine kinase on lymphatic endothelial cells for the therapy of colon cancer lymph node metastasis. Neoplasia. 2006; 8(9):747-757.

47. Joshi B, Bastiani M, Strugnell SS, Boscher C, Parton RG and Nabi IR. Phosphocaveolin-1 is a mechanotransducer that induces caveola biogenesis via Egr1 transcriptional regulation. J Cell Biol. 2012; 199(3):425-435.

48. Gould ML, Williams G and Nicholson HD. Changes in caveolae, caveolin, and polymerase 1 and transcript release factor (PTRF) expression in prostate cancer progression. The Prostate. 2010; 70(15):1609-1621.

49. Hayer A, Stoeber M, Ritz D, Engel S, Meyer HH and Helenius A. Caveolin-1 is ubiquitinated and targeted to intralumenal vesicles in endolysosomes for degradation. J Cell Biol. 2010; 191(3):615-629.

50. Liang CC, Park AY and Guan JL. In vitro scratch assay: a convenient and inexpensive method for analysis of cell migration in vitro. Nat Protoc. 2007; 2(2):329-333.

51. Santilman V, Baran J, Anand-Apte B, Evans RM and Parat M-O. Caveolin-1 polarization in transmigrating endothelial cells requires binding to intermediate filaments. Angiogenesis. 2007; 10(4):297-305.

52. Bruyère $F$ and Noël $A$. Lymphangiogenesis: in vitro and in vivo models. FASEB J. 2010; 24(1):8-21.

53. Berndt $S$, Bruyère $F$, Jost $M$ and Noël A. (2008). In vitro and in vivo models of angiogenesis to dissect MMP functions. The Cancer Degradome: Springer), pp. 305-325.

54. Michaelis M, Michaelis UR, Fleming I, Suhan T, Cinatl J, Blaheta RA, Hoffmann K, Kotchetkov R, Busse R and $\mathrm{Nau} \mathrm{H}$. Valproic acid inhibits angiogenesis in vitro and in vivo. Molecular pharmacology. 2004; 65(3):520-527.

55. Schmittgen TD and Livak KJ. Analyzing real-time PCR data by the comparative CT method. Nat Protoc. 2008; 3(6):11011108. 